\title{
New Challenges for Participation in Participatory Design in Family, Clinical and Other Asymmetrical, Non-work Settings
}

\author{
Olav W. Bertelsen ${ }^{1}$ and Per-Olof Hedvall ${ }^{2}$ \\ ${ }^{1}$ Dept. of Computer Science, Aarhus University, Aabogade 34, \\ DK-8200 Aarhus N, Denmark \\ olavbecs.au.dk \\ ${ }^{2}$ CERTEC, Lund University, P.O. Box 118, SE-221 00 Lund, Sweden \\ per-olof.hedvallecertec.lth.se
}

\begin{abstract}
Participatory design (PD) has taken as its ideal that designers and users should engage in an equal language game. When we apply PD in contexts where some of the users involved are weak, ill, or have impairments, this assumed equality can no longer be an ideal. The workshop explores new ideals for participatory design in non-work settings with highly heterogeneous user constellations.
\end{abstract}

Keywords: Participatory Design, Non-Work Setting, Asymmetry, Heterogeneity.

\section{About the Workshop}

Participatory design has the point of view that designers and users should engage in an equal language game. The ambition has been that equality in design is possible to achieve by creating certain conditions for the design activities. Whether or not this ideal has ever been met is a big question, but when PD operates in contexts where some of the involved users are weak, ill, or have impairments, we are clearly confronted with a situation where this assumed equality is no longer an ideal that can be reached. Examples of such contexts are:

Premature newborns. Grönvall et al. [1] have worked with the design of IT enhanced environments for premature infants. The doctors and nurses are at work and have clear perspectives of the therapeutic strategies they want the environment to support; the parents are in the middle of a severe life crisis of which they probably do not have any previous experience; the child is fighting for survival. They are all users but can be involved in design in very different ways.

Phobic patients. Bering [2] designed a mobile device to support cognitive therapy for phobic patients. The fragility of the patients made it difficult to involve them, and any exposure to the triggers of phobic reaction would interfere with their therapeutic programs.

Families that have children with complex communication needs. Children with these needs are often challenged by asymmetrical terms for communication and 
interaction in everyday family life [3]. This affects the whole family. Thus, even when the child is be the potential "user" of a design, the entire family needs to be engaged in the design process.

Erotic intimacy. As pointed out by Bertelsen and Petersen [4], the increased presence of information technology in the private sphere has become a limiting factor for erotic intimacy today. Designing solutions for this problem is a challenge to established methods in participatory design.

In early participatory design, it made sense to take a power struggle perspective and aim for user-empowerment in the design of better computer support. As contexts change, however, other perspectives should be introduced to maintain participatory design as a realistic pragmatic design approach. Classical activities developed in participatory design, such as mock-ups, organizational games and other activities that rely on breakdowns in the flow of simulated action as a source of shared sense making may not be useful. Instead new activities such as diary studies, fictitious users, therapists as mediators, various forms of probing, and completely new forms of participation have to be invented.

In developing an understanding of participatory design in these contexts, new and old theoretical frameworks may be useful. Activity theory has been used to make sense of early participatory design [5] and may have potential in this context. Actor network theory, distributed cognition and communities of practice are other examples that can be revisited. This "new participatory design" is not only a challenge to participatory design but is also a potentially transformative resource for some therapeutic, family and care-oriented domains. Furthermore, it contributes to the fields of accessibility and impairments [6].

The workshop seeks to approach new participatory design by inviting position papers, informative design cases, techniques, methods and theoretical analyses. The workshop will be organized as a mixture of presentations, discussions and various breakout activities depending on the number of participants and the submitted work. Proceedings from the workshop will be edited and published after the meeting [7].

\section{References}

1. Grönvall, E., Marti, P., Pollini, A., Rullo, A., Bertelsen, O.W.: Palpable Time for Heterogeneous Care Communities. In: Proc. Crit. Comp. ACM Press, New York (2005)

2. Bering, P.F.: Cognitive-behavioral Therapy using Mediating Instruments. Unpublished master's thesis, Department of Computer Science, Aarhus University (2005)

3. Beukelman, D.R., Mirenda, P.: Augmentative \& Alternative Communication - supporting children \& adults with complex communication needs. Brookes, Baltimore (2005)

4. Bertelsen, O.W., Petersen, M.G.: Erotic Life as a New Frontier in HCI. In: Lew, M., Sebe, N., Huang, T.S., Bakker, E.M. (eds.) HCI 2007. LNCS, vol. 4796. Springer, Heidelberg (2007)

5. Bødker, S.: Through the Interface. LEA (1991)

6. Hedvall, P.-O.: Xings for augmented family Communication. Full paper and poster presented at ISCAR 2008, San Diego (2008)

7. http://www.daimi.au.dk/ olavb/NewPD/ 